\title{
The International Register of Potentially Toxic Chemicals (IRPTC) of UNEP
}

\author{
by \\ ALEXANDER I. KUCHERENKO, D.Sc.(Moscow) \\ Senior Scientific Officer, International Register of Potentially Toxic Chemicals, UNEP, \\ Palais des Nations, 1211 Geneva 10, Switzerland
}

$\&$

JAN W. HUISMANS, D.Sc.(Utrecht)

Director, International Register of Potentially Toxic Chemicals, UNEP, Palais des Nations, 1211 Geneva 10, Switzerland.

\section{INTRODUCTION}

The deterioration of environmental quality, which began when Man first became aggregated into villages and used fire, has existed as a serious problem under the ever-increasing impacts of exponentially-increasing population and the ravages of the industrialized society.

The Middle of the Twentieth Century witnessed a rapid expansion of the chemical industry and, with it, the intrusion of chemical technology into practically all branches of the economy and into every-day life. Today, Man is synthesizing new chemicals which do not occur in Nature, and is using them in industry and agriculture as well as for medicines and a wide range of domestic purposes. Indeed, their proper use has enhanced the quality of life of millions of people.

At the same time, pollution of the environment by chemicals has resulted in serious impairment of human health and in considerable ecological damage. Some of these potential hazards to Man and his environment are recognized, but others may only appear after a considerable time-lapse. It is therefore of the utmost importance that, if the hazards outweigh the benefits which chemicals bring, then their use has to be critically and objectively assessed. Many countries have passed laws and regulations regarding evaluation and control of chemicals in the environment, and require information to be submitted to national authorities before chemicals can be manufactured or used. Some of this information has been confined to certain institutions in a limited number of countries, and is not easily available to others.

The need for adequate information to assess the potential hazards posed by chemicals to Man's health and the environment has become clearly recognized very widely in the world. Further knowledge about the amounts of particular chemicals produced in the world, the pattern of their use, and their properties and effects on Man, living organisms, and the environment, as well as their distribution and transformation in the environment, is required. Improved access to information on national laws and regulations to control the use of chemicals is also necessary.
There exist, all over the world, various information systems on chemicals which are not always at all readily accessible to the experts and authorities who are responsible for regulatory decisions. Frequently the information contained in such systems is not adequately suited to the needs of decision-makers. Until lately, there has been no international institution to collect and disseminate this information on a global scale for all those who deal with the control of hazards posed by chemicals to human health and the environment.

\section{IRPTC, ITS OBJECTIVES AND STRATEGIES}

At the United Nations Conference on the Human Environment, held in 1972 in Stockholm, it was recommended that plans be developed for an International Register of Data on Chemicals in the Environment, based on collection of available scientific data. Following this recommendation, the Governing Council of the United Nations Environment Programme (UNEP) decided, in 1974, that urgent steps should be taken for the establishment of both a chemical register and an information exchange network (UNEP, 1978). As a result of this decision, two meetings of experts were convened in 1975 at which guidelines, objectives, and a set of strategies, for such a register were formulated.

Since its creation in 1976, the International Register of Potentially Toxic Chemicals (IRPTC) has been guided by the decisions of the Governing Council and the recommendations of both those meetings. The following objectives for the IRPTC Programme Activity Centre were approved by the Governing Council at its Sixth Session, in 1978:

(i) To facilitate access to existing data on the effects of chemicals on Man and his environment, and thereby contribute to a more efficient use of national and international resources that are available for the evaluation of effects of chemicals and their control;

(ii) On the basis of information in the Register, to identify the important gaps in existing knowledge 
on the effects of chemicals, and call attention to the need for research to fill those gaps;

(iii) To identify, or help identify, potential hazards from chemicals, and improve the awareness of such hazards;

(iv) To provide information about national, regional, and global policies, as well as regulatory measures, standards, and recommendations, for the control of potentially toxic chemicals.

To achieve these objectives, the following activities have been foreseen by the Governing Council:

A. To render the IRPTC Programme Activity Centre capable of handling data and answering questions;

B. To involve correspondents designated at the national, regional, and sectoral levels in the operations of IRPTC;

C. To build a network of participating data systems, which may make their files available to the IRPTC Programme Activity Centre for incorporation in its central data-files, or may respond directly to users' queries;

D. To develop and continuously update computerized central data files; and

E. To publish selected information on chemicals.

The Governing Council of UNEP also requested the Member States to assist the Executive Director in establishing the network by appointing National Correspondents, ${ }^{*}$ and to improve their national mechanisms in terms of personnel, facilities, and organization - so as to enhance the capability of IRPTC to fulfil its task efficiently and effectively.

\section{NETWORK PARTNERS}

The International Register of Potentially Toxic Chemicals has been designed to operate on the basis of network arrangements for information exchange, and on development of central files on chemicals which are called data profiles (Huismans, 1978, 1980). From the beginning of its activities, the identification of network partners and the implementation of effective collaboration, have been priority tasks for IRPTC.

The potential partners in the network can be identified as:

1) The Central Unit, or Programme Activity Centre (PAC);

2) The IRPTC National Correspondents;*

3) Some national and international institutions; and

4) Industries and external contractors.

The Central Unit, assisted by a Scientific Advisory Committee and ad hoc expert consultants for special tasks, operates the network, sets the procedures for exchange of information, and communicates with countries and institutions. In accordance with the mandate given to IRPTC as a component of UNEP, it will try to improve the coordination of international activities in the field of information exchange, or to initiate new activities where there is a gap causing deficiencies and/or inadequate action.

*an example of which is described above, on pp. 57-8. - Ed.
IRPTC assists in establishing national registers, providing special training and assistance (where necessary) to ensure effective participation of all interested national institutions and to improve understanding of IRPTC's data presentation. For this reason, a series of regional workshops was organized in 1979,1980 , and 1981 , for National Correspondents of the Asian and Pacific Region, the Africa and West Asia Regions, and the Latin America Region.

In the operation of IRPTC's Central Unit, National Correspondents play an important role by providing: information on new or planned legislation to control chemicals; newly-prepared regulations and recommendations regarding chemicals; new studies on chemicals causing concern in respect to human health and the environment; and reports on accidents and incidents involving chemicals that have led to official enquiries. They also give advice on expertise relevant to IRPTC, and distribute information processed by IRPTC.

Working relationships have also been (and are still being) established with other network partners-such as international organizations, national governmental institutions, scientific research institutes, and industry - with a common interest in chemical safety. The importance of the role of network partners in information collection and in data-profiles development, cannot be overemphasized.

Several mechanisms for collaborative production of data profiles for chemicals can be envisaged, and various levels of assistance to IRPTC can be suggested. Thus there could be assistance from network partners to IRPTC in carrying out literature searches and collection of relevant documents, as well as in the preparation of texts. A particularly productive cooperation would consist of the preparation of data profiles for chemicals, using either machine-readable worksheets (now under development) or more textual worksheets currently used by IRPTC staff.

The study and review of data profiles prepared by IRPTC could be helpful, and a possibility to compare IRPTC's chemically-related sources of information with each network partner's bibliographical data-base could also be most useful and mutually beneficial.

\section{DATA PROFILES FOR CHEMICALS}

The development of central files containing information adequate for an understanding of health and environmental hazards caused by toxic chemical substances, has been constantly given priority attention by IRPTC. The tentative list of attributes (characteristics) of chemicals, prepared for [the forthcoming] IRPTC in 1975, was further developed and better-defined during a subsequent study which was carried out with the participation of an international group of expert consultants. This study formed the foundation for storage and retrieval of data in the IRPTC central data system, and has been initially employed in the preparation of data profiles for chemical substances. Data profiles for some 60 chemicals were prepared and published in 1979 as illustrative examples of typical IRPTC output (IRPTC, 
TABLE I. IRPTC Data Profile Structure.

1. Identifiers and Properties

2. Production/Trade

3. Production Processes

4. Use

5. Pathways into the Environment

6. Concentrations

- Loss/Persistence

. Concentrations

Human Intake

7. Environmental Fate Test

. Biodegradation/Biotransformation

. Photodegradation

. Hydrolysis

Sorption

Evaporation

Oxidation

Model Ecosystem Studies

8. Environmental Fate

9. Chemobiokinetics

- Absorption

Distribution

. Bioconcentration Factor

. Metabolism
Excretion

10. Mammalian Toxicity

11. Special Toxicity Studies

Biochemical Interactions

- Carcinogenicity

. Mutagenicity

. Neurotoxicity

Behaviour

Sensitization

. Inter acting Agents

Primary Irritation

. Immunotoxicity

. Reproduction

Teratogenicity

12. Effects on Organisms in the Environment

. Aquatic Toxicity

Terrestrial Toxicity

13. Sampling/Preparation/Analysis

14. Spills

15. Treatment of Poisoning

16. Waste Management

17. Recommendations/Legal Mechanisms

TABLE II. Register Subfile on Mutagenicity.

\begin{tabular}{|c|c|}
\hline \multicolumn{2}{|c|}{ Test Description } \\
\hline Study type & Exposure frequency \\
\hline Organism & Exposure comment \\
\hline Route & Purity grade and/or percentage \\
\hline Sex & Impurities \\
\hline Life-stage & Vehicle/solvent \\
\hline Number of organisms exposed & Description of the test substance/particle size \\
\hline Number of organisms in the control group & Isotope/labelled compound \\
\hline Species/strain/system description & Test conditions/method \\
\hline Exposure dose/concentration & \\
\hline Exposure period & \\
\hline Exposure type & \\
\hline \multicolumn{2}{|c|}{ Test Results } \\
\hline Organ/system/tissue affected & Number of exposed affected \\
\hline Effect & Number of controls affected \\
\hline Sex affected & Effect comment \\
\hline Reversibility/irreversibility of the effect & General comments \\
\hline Time of onset of the effect & Evaluations and appraisals \\
\hline
\end{tabular}

1979)*. With the assistance of subcontractors, National Correspondents, and other contributing network partners (including chemical manufacturers), IRPTC staff are now preparing data profiles for approximately 350 chemicals.

The data profiles enable the expert user, world-wide, to identify what is known about a particular substance in terms of its chemical, physical, environmental, and toxicological, characteristics relevant for hazard assessment. In addition, they provide information on production and consumption, use, spills, treatment of poisoning, and waste management-as well as on recommendations and legal mechanisms for control of hazards posed by chemicals. All information in a data profile is presented in extracted and condensed form together with the sources from which it was obtained. At present, an IRPTC data profile consists of seventeen attributes or files. Each of these files can be divided into subfiles,

\footnotetext{
*Reviewed by Dr Norman W. Moore, our Advisory Editor in matters pertaining to Pesticides and Toxicants, in the preceding issue (Environmental Conservation, Vol. 8, No. 4, p. 337 , 1981).-Ed.
}

with presentation of relevant data-records involving a complete item of information. The main content of an IRPTC data profile is shown in Table I.

The following basic entries may be included, for example, in the subfile on mutagenicity: exposure dose or concentration; exposure period and type; route of administration; organism, sex, and life-stage, with numbers in control and experimental groups; target organ(s), showing the effects described, etc. The effect(s) are reported as described by the author. Evaluations and appraisals are included in subfiles when they have been issued by expert panels representing the United Nations, international, governmental, or nongovernmental, scientific organizations. As an illustrative example, a full record of the subfile on mutagenicity is presented in Table II.

Detailed instructions for the selection and presentation of data for the Register were developed and published in 1979, and, after recent extension and modification, they are now being widely used for data profiles development by the IRPTC Programme Activity Centre (IRPTC, 1979 and in press). The instructions 
allow for uniform data input and correct description of the particular properties or effects of chemicals, as well as of any legal or regulatory information available.

Another aim of the instructions is to provide assistance to users of data profiles towards understanding fully the information contained in them. In order to provide reliable, relevant, and sufficiently detailed, information to assess chemical hazards in the environment, the corresponding IRPTC files and subfiles may need further improvement regarding their content and structure. In this respect, assistance from contributing network partners and users would be greatly appreciated.

\section{SOURCES AND QUALITY OF DATA}

The identification of all relevant sources of information on chemicals, organized in one, several, or all datafields, and the ascertaining of their quality, are necessary for the Register. The importance of the reliability of data entered into the IRPTC data-bank cannot be overemphasized, so preference is given to information which has been evaluated by international and national groups of experts.

IRPTC has in its files a fast-growing collection of national and international criteria documents, monographs, and dossiers on chemicals, as well as national regulations and international conventions and guidelines concerning chemicals. In cases where secondary documents containing evaluated information do not exist, IRPTC staff and network partners carefully select and review primary sources of data-always according to the instructions for data selection and presentation. In addition, IRPTC seeks advice, as appropriate, from individual consultants, panels of experts, and international organizations.

\section{LIST OF SELECTED CHEMICALS}

Clearly, in building up an information system such as an environmental chemicals' data-bank, it would not be possible to consider all chemicals at once or, indeed, to devote equal attention to each of them. It is extremely difficult to select chemicals for priority treatment and the preparation of comprehensive data-profiles. Selection criteria can be used for each chemical, such as production quantity and main uses, toxicity to Man, ecotoxicity, and persistence and biodegradability. The second approach for the preparation of a priority list is to identify chemicals for which concern has been expressed at the national and/or international level. This includes lists of chemicals that are widely used, poisons, chemicals to which wide sectors of the population or workers are exposed, pesticides, etc.

In preparing an integrated list of chemicals which will gradually grow, IRPTC has tried to identify the largest possible number of chemicals of international significance. The IRPTC Working List of Selected Chemical Substances at present includes approximately 350 chemicals, of which 160 are agro-chemicals; but it is by definition open-ended, and will undergo considerable expansion on the basis of proposals made by National
Correspondents, the International Programme on Chemical Safety, and IRPTC network partners.

\section{USERS AND QUERY-RESPONSE SERVICE}

The most important user-group of IRPTC is represented by national authorities that are responsible for protection of human health and the environment. Decisions to regulate or control chemicals must be based on 'best-informed' judgement. The International Register aims at providing its readers with a reliable, up-to-date and comprehensive presentation of information necessary to assess the risk caused by chemicals to Man and his environment.

The scientists involved in experimental research can hardly expect, from a computerized data-bank such as that of IRPTC, the detailed information that would obviate for them the necessity of reading the original sources of data. However, they can use the Register to identify priority chemical substances which may have the potential for being hazardous, and on which little or no pertinent research has been performed to elucidate this potential. International bodies, such as the International Programme on Chemical Safety, could use information from the Register as a basis for production of evaluation documents, as well as for identification of gaps in knowledge and for the planning of future studies.

Information contained in the Register is also of interest to both government and industry in the development of guidelines and recommendations on chemicals' control, or in the determination of likely effects when planning chemical research.

A Query-Response Service is now in operation and provides, on request, information on specific chemicals. Questions may be answered by the Central Unit, using information contained in its data profiles and library system, through searches of on-line data bases, or with the assistance of partners in the network when relevant information is not available in the Register. Other international bodies or expert consultants may help in answering questions.

\section{DATA MANAGEMENT AND IRPTC PUBLICATIONS}

Growth of documentation received from many sources necessitates optimal access to the relevant data which it contains. Also, data profiles have to be processed and stored in a computer, using an adequate software package allowing easy updating and retrieval of information. The terminals now in use in the IRPTC Central Unit are connected to the International Computing Centre (ICC), Geneva. Access to relevant on-line information systems has been established.

Having reached the stage of computerization of the data compiled on chemicals, and taking into consideration several criteria, IRPTC has decided to implement its information bank through the Data Base Management System, 'ADABAS', which is now being adapted to provide the services required by the Register (Gilbert \& Huismans, 1982).

Some data bases have already been organized and stored. Foremost among these is the Register Index, 
published every four months, which consists of the IRPTC Working List of Selected Chemicals, accompanied by pointers showing on which data fields IRPTC has information in its files. The most important data base contains the IRPTC Library records. Over 2,000 documents have been indexed up to now, according to a format and a thesaurus developed by IRPTC.

In addition to production of data profiles, IRPTC also publishes a Bulletin which contains information on IRPTC activities, other activities of UNEP, international and national organizations related to chemical safety, and other current intelligence information on chemicals. National Correspondents actively participate in providing information for the Bulletin and distributing it within their respective countries. Other network partners also provide new information for inclusion in the Bulletin, which is published in four languages and issued twice yearly, although it is planned to increase the frequency of publication to three issues per year. Further scientific publications and data compilations are foreseen for the near future.

\section{SUMMARY}

Until recently there has been no international register or international network linking national registers for the exchange of information on, and for, chemical hazard assessment and control. The International Register of Potentially Toxic Chemicals (IRPTC) was established by the United Nations Environment Programme (UNEP) in 1976 and is now in full operation.

The objectives assigned to the Register concern the establishment of a global network of contributing partners through which it can develop its data-bank containing relevant information for an assessment of environmental hazards caused by chemicals, and disseminate this information to decision-making bodies, national authorities, international organizations and other institutions, and to the scientific community that is concerned with the evaluation and control of chemicals in the environment.

The IRPTC operations involve preparation of data profiles for chemicals, the development of a computerized data storage and retrieval system, a queryresponse service, and the publication of a 4-monthly Register Index, a periodical Bulletin, and other documents. These contain information on chemicals, international and national activities related to issues of chemical safety, and also legislative and regulatory measures for protection of the heal th of humans and of the environment from the noxious effects of chemicals.

\section{REFERENCES}

HUISMANS, J. W. (1978). The International Register of Potentially Toxic Chemicals (IRPTC): Its present state of development and future plans. Ambio, 7(5-6), pp. 275-7.

HUISMANS, J. W. (1980). The International Register of Potentially Toxic Chemicals. Ecotoxicology and Environmental Safety, 4, pp. 393-403.

GILBERT, M. \& HUISMANS, J. W. (1982). The International Register of Potentially Toxic Chemicals: Its usefulness for the assessment and control of hazards from chemicals. Pp. 263-74 in Education and Safe Handling in Pesticide Application (Ed. E. A. H. van Heemstra \& W. F. Tordoir). Elsevier Scientific Publishing Company, Amsterdam, The Netherlands: xiv +302 pp., illustr.

IRPTC (1979). Instructions for the Selection and Presentation of Data for the International Register of Potentially Toxic Chemicals, with Sixty Mlustrative Chemical Data Profiles. (Register Attribute Series No. 2.) IRPTC, Geneva, Switzerland: $x i i i$

IRPTC (in press). International Register of Potentially Toxic Chemicals, Part A. IRPTC, Geneva, Switzerland.

UNEP (1978). United Nations Environment Programme: Compendium of Legislative Authority. Pergamon Press, Oxford, England, UK: $287 \mathrm{pp}$.

\section{The Evaluation of Ambient Air Quality}

The evaluation of air quality by the use of an airquality index has been the focus of much discussion in environmental science during recent years. Several formulations of different air-quality indices have been developed in China, almost exclusively applied to the observation of air-quality conditions and trends in cities rather than for the daily reporting of air quality to the public. The two indices published by the Author (Yao, 1980) have received much attention, and have found effective application in some localities. However, the Author is of the opinion that a comparison of the air quality in different cities can be made only on the basis of uniform air-quality monitoring criteria and methodology, and by the use of a uniform air-quality index.

In the United States, the Pollutant Standard Index (PSI) has been stipulated as a nation-wide uniform index for the daily reporting of local air-quality to the general public, for the analysis of its variation through years, and for the ranking of cities according to the seriousness of their air pollution problems (Anon., 1977; Council on Environmental Quality, 1979, 1980).

Based on monitoring data from one station that re- ported the worst of all recorded results, an arbitrary airquality index was used to report air pollution twice-aday in Melbourne, Australia (Gilpin \& Hartmann, 1981). The index was used to demonstrate the number of days in a year on which light, significant, or heavy, air pollution occurred.

The Author now regrets to note that the four positive numbers in the last line in Table III of his paper published in Environmental Conservation (Vol. 7, No. 3, p. 226, Autumn 1980), namely:
$0.41 \quad 15.39$
0.82
15.42

should instead read:

$\begin{array}{llll}1.41 & 15.25 & 1.82 & 15.42 .\end{array}$

Yao Zhi-qi

Associate Professor and Deputy Director

Department of Environmental Health

School of Public Health

Shanghai First Medical College

Shanghai 200032

People's Republic of China. 